\title{
THE TOLERANCE OF AN EXTENSIVE COLLECTION OF GARLIC (ALLIUM SATIVUM L.) GERMPLASMS TO SALT STRESS - A SUSTAINABLE SOLUTION TO SALT STRESS
}

\author{
AHMAD, J. ${ }^{1}-$ WANG, H. ${ }^{1 \#}-$ SONG, J. ${ }^{1}-$ NUERAWUTI, M. ${ }^{1}-$ ZHANG, X. ${ }^{1}-$ YANG, W. ${ }^{1}-$ MA, L. ${ }^{2}-$ \\ LI, X. X. ${ }^{1^{*}}$ \\ ${ }^{I}$ Institute of Vegetables and Flowers, Chinese Academy of Agricultural Sciences; Key \\ Laboratory of Biology and Genetics Improvement of Horticultural Crops, Ministry of \\ Agriculture, Beijing 100081, China \\ (e-mails: jalil.ahmad1300@gmail.com-J.Ahmad,wanghaiping@caas.cn-H.Wang, \\ songjianping@caas.cn-J.Song,2780812743@qq.com-M.Nuerawuti, \\ zhangxiaohui01@caas.cn-X. Zhang,wenlongyang@caas.cn-W. Yang)
}

${ }^{2}$ Shandong Engineering and Technology Research Center for Garlic, Shandong Jining, 272200, China

(e-mail: 52569370@qq.com-L.Ma)

${ }^{\#}$ Co-first author

*Corresponding author

e-mail: lixixiang@caas.cn

(Received $14^{\text {th }}$ Dec 2020; accepted $18^{\text {th }}$ Mar 2021)

\begin{abstract}
Salinity is a serious problem that limits growth and yield of many agricultural crops worldwide. There is a need for a sustainable long -term solution to this problem. In this study, 354 diverse garlic germplasms were evaluated for their salt -tolerance at the seedling stage by being exposed to $\mathrm{NaCl}$ $(0.25 \mathrm{~mol} / \mathrm{L})$ stress. The salt injury index (SII) along with several plant growth parameters were investigated. The results showed a wide variation of SII from 16.51 to 98.15 among these accessions. All accessions were classified into five groups according to their SIIs, corresponding to different grades of the tolerance to salinity. Among them, two highly tolerant and twenty-four salt-tolerant accessions were screened out. The response of distincit germplasms to salt stress was somewhat different in various trait indices. Moreover, an extremely significantly negative correlation was observed between SII and agronomic traits (PH, LL, LW and RHL) and physiological traits (gs, A, E, Ch). This study provides sustainable solution, original salt-tolerance evaluation technology and valuable materials for the garlic salt-tolerant genetic improvement.
\end{abstract}

Keywords: Allium sativum $\mathrm{L}$., $\mathrm{NaCl}$ stress, seedling growth, salt injury index, clustering analysis, correlation analysis

\section{Introduction}

Various plants show variable responses to different environmental stresses including abiotic and biotic stresses. Abiotic stresses are a result of non-living components of the ecosystem, such as temperature, drought, waterlogging, salinity, nutrient deficiency, gaseous pollutions, metal toxicity, and so on. Of these, salinity stress is a severe threat to agriculture and food security as one-third of the irrigated land on the earth is affected by salinity (Machado and Serralheiro, 2017). The saline or sodic soils comprise about $6 \%$ of the total land all over the world (Munns, 2002). Salinity stress highly declines the crop growth and yield of many field crops (Teshika et al., 2019) and some vegetables, such as garlic, pea, okra, tomato, eggplant, peppers, carrot, cauliflower and potato (Francois, 1994; Shahbaz et al., 2012; Tanveer et al., 2020). Secondary salinization is 
becoming more and more serious in the continuous cropping protected vegetable production (Shahbaz et al., 2012).

Secondary soil salinization is typically caused by an imbalance between transpiration and water inputs from rainfall and irrigation. This imbalance comes in combination with soil characteristics that impede leaching (Cocks, 2001; Mateo-Sagasta and Burke, 2011). Wrong irrigation practices (e.g., waterlogging) and misplanning (e.g., temporal over irrigation) are major drivers of soil salinization (Cocks, 2001; Wichelns and Qadir, 2015). Other factors include the use of unlined canals and reservoirs, and vegetation clearing, in combination with inadequate drainage that filters salts into the groundwaters (Ritzema, 2016), from where the dissolved salts can be remobilized to the upper layers of the soil by means of upward water flows during dry periods (Crescimanno and Garofalo, 2006; Bhutta and Smedema, 2007). The quality of the irrigation water and rational application of fertilizer are also very important to avoid secondary salinization.

Salinity excess affects plant growth through many aspects of physiological and biochemical processes in the plant. Saline stress results in osmotic pressure and ionic stress, which impair the pivotal cellular function. Osmotic stress minimizes the water availability, causes dehydration and stomatal closure and slows down the rate of biochemical reactions (Acosta et al., 2017; Munns, 2002). Salinity stress alters some of the physiological process of plants, such as respiration rate, mineral distribution, membrane stability and turgor pressure (Hasegawa, 2013; Garrote et al., 2015). Shoot growth and early flowering are also influenced by salinity due to the inhibitory effect of salt in growing points on cell division and cell enlargement (Alom et al., 2016).

Plants withstand the salt stress by several mechanisms including high complexity or low complexity mechanisms. The former one is thought to be involved in alterations of many biochemical pathways. The later one is believed to induce coordination for the preservation of complex processes (Nasri et al., 2015). The high-complexity mechanism protects the main processes such as respiration and photosynthesis and retains important features such as plasma membrane interactions, cytoskeleton, cell wall (Gupta and Huang, 2014) and chromatin structural changes such as polyploidization, DNA methylation, DNA removal or amplification of unique sequences (Walbot and Cullis, 1985). Anyway, the genetic mechanism may be the major controller behind the different mechanisms.

Economic reasons or scarcity of freshwater are the major limitations to the soil salinization recovery in many situations. The only possible feasibility is the development of salinity tolerant varieties (Hoque et al., 2015), which could be developed through the germplasm selection and genetic improvement. Still, the success is related to the extent of genetic variation of tolerance to salinity among available germplasm for a crop species. Simultaneously the complexity of traits, limited knowledge about physiology and genetics of tolerance related attributes, and shortage of efficient selection domain are the major constrains to salinity tolerance breeding programs. What is more, optimizing saline conditions in the field and greenhouse for identification could be temporary and expensive.

Genetic characterization of useful germplasm is the first step towards releasing tolerant cultivars. Many researchers have demonstrated that evaluating the salt tolerance at the vegetative stage of a plant species is important to determine the ultimate tolerance of the species (Aslam et al., 1993; Uddin and Hossain, 2018; Kakar et al., 2019; Sikder et al., 2020). The early vegetative stage of a crop is regarded as the most dangerous stage, where plant yield is determined by (Uddin and Hossain, 2018) reported that 
selection of a crop is noted to be important at the vegetative stage for at least two reasons. Firstly, under controlled conditions in limited space, vegetative growth rates can be calculated easily and relatively in a short time (4-6 weeks). Secondly, under saline conditions, rapid vegetative development reflects a plant response to the stress environment and its capacity to produce additional resources for growth. The difference in salinity tolerance at vegetative stage has been reported in vegetables crops (Blum, 2018). Furthermore, a more significant yield loss has been reported when plants were exposed to salinity at the early growth stage than the divulgence at a later part of growing (Machado and Serralheiro, 2017).

A few researches have been done on salt tolerance of garlic. Francois (1994) reported that yield components (bulb weight and diameter) were reduced with increasing salinity, as well as the percent of solids which is a major component of bulb quality. Shoot dry weight was less susceptible to salinity stress than bulb weight, but higher concentration of chlorine, sodium and calcium accumulated in leaf tissues than in bulb by a smallscale experiment. Saline water irrigation significantly decreased the number of leaves and plant height of garlic (Shama et al., 2016).

Therefore, the main objective of this study was to evaluate the salt-tolerance of garlic germplasm at the seedling stage based on agronomic characteristics in a pot culture system on a large scale for the first time and understand the genetic variation of salinity tolerance and the relationship between the salt-tolerance and the agronomic/physiological characteristics for garlic genetic improvement of salt-tolerance and effective utilization of salt-tolerant garlic varieties in saline soil exploitation.

\section{Materials and methods}

The garlic germplasm of 354 accessions collected from in 15 province of China and 30 other countries were conserved in the national field gene bank of vegetative propagation vegetables on Lang fang farm of the Institute of Vegetables and Flowers, Chinese Academy of Agricultural Sciences in the suburb of Beijing, China. The experiment was conducted in a solar greenhouse using a pot culture method during early Spring and were arranged according to a completely randomized block design for each accession under stress and control with three replicates. Ten garlic cloves for each replicate were sowed in plastic pots $(8 \times 8 \mathrm{~cm})$ containing peat and vermiculite $(1: 1)$. Hoagland's solution was used as a source of nutrient. Each pot with garlic cloves was irrigated with irrigation water in the first week and with the 1/2 fold Hoagland's solution prepared with irrigation water during the second week and the third week after sowing once a week. Each pot for salt stress was subjected to $1.5 \%$ concentration of $\mathrm{NaCl}(0.25 \mathrm{~mol} / \mathrm{L})$ prepared with irrigation water starting from the beginning of the fourth week after sowing, continuously four weeks, once in each week. In contrast to salt treatment, each pot under the control was irrigated with irrigation water at the same frequency.

\section{Investigation of salt injury grades and calculation of salt injury index}

Visual salt injury grades for each plant in different accessions was determined after one week after finishing the salt treatment according to the following standard we modified based on the method by IRRI (2014) (Table 1).

Eight plants per replicate for each accession were scored. Salt injury index (SII) were calculated by the following formula (Eq. 1): 


$$
\mathrm{SII}=\frac{\sum(5 \times n)}{\mathrm{N} \times 5} \times 100
$$

where: $\sum=$ The sum of the product of each grade value and the number of plants at each grade; $\mathrm{s}=$ the value of each grade; $\mathrm{n}=$ the number of plants at each grade; $\mathrm{N}=$ the total number of plants investigated; $\mathrm{S}=$ The highest value of injury grade.

Salt tolerance was classified according to clustering analysis result based on the average SII value of three replicates for each accession.

Table 1. Modified standard of visual salt injury of each plant at the seedling stage

\begin{tabular}{c|c}
\hline Grade & Observation of visual salt injury (VSI) \\
\hline 1 & Plant grows normally, and only the leaf tips of 2 leaves, or less than 2 leaves of a plant are yellowing \\
3 & Plant grows basically normal, and the leaf tips of $3 \sim 4$ leaves are yellowing or curly slightly \\
5 & Plant growth is retarded partly; $5 \sim 6$ leaves yellowing or curly \\
7 & Plant growth is severely retarded or even ceases; $6 \sim 7$ leaves of a plant are yellowing or becoming dry \\
9 & More than 7 leaves are yellowing and severe, the whole plants are dead or dying \\
\hline
\end{tabular}

\section{Measurement of agronomic traits}

Plant height (PH), leaf length (LL), leaf width (LW), total leaves number and healthy leaves number of 354 accessions were measured individually in the eighth week after sowing. The ratio of healthy leaves number to total leaves number per plant was calculated by the formula (Eq. 2):

$$
R H L=\frac{\text { Healthy leaves number }}{\text { Total leaves number }} \times 100
$$

In order to understand the effect of salt stress on plant growth change, the relative value of plant height (RPH), leaf length (RLL), leaf width (RLW) and ratio of healthy leaves (RRHL) under salt stress and under control were calculated referred to the following formula (Eq. 3):

$$
R P H=\frac{\text { Plant height under stress }}{\text { Plant height under control }}
$$

\section{Measurement of physiological indexes}

Sub-stomatal $\mathrm{CO}_{2}$ concentration $\left(\mathrm{Ci}, \mu \mathrm{mol} \mathrm{mol}^{-1}\right)$, assimilation/respiration $(\mathrm{A}, \mu \mathrm{mol}$

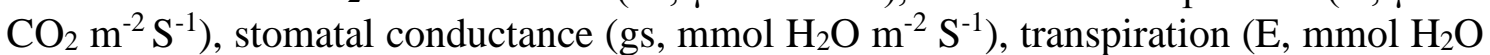
$\mathrm{m}^{-2} \mathrm{~S}^{-1}$ ) of 81 accessions selected randomly from 354 accession as representatives was determined by CIRAS-3 portable photosynthesis system (PP system, Amsbury, MA, USA) after seven weeks of sowing in order to shorten measurement time and minimize experiment error. Data were automatically recorded by the CIRAS-3 every $5 \mathrm{~s}$. The $\mathrm{CO}_{2}$ concentration $\left(380 \mu \mathrm{mol} \mathrm{mol}^{-1}\right)$, relative humidity $(60 \%)$, and leaf temperature $28{ }^{\circ} \mathrm{C}$ were maintained using an automatic control device on the CIRAS-3. Red- blue light (90\%: 10\%) was provided by the LED light unit in the CIRAS3.

The Soil and Plant Analyzer Development (SPAD) values can present the relative content of chlorophyll and be measured by the portable SPAD-502m emitting red light $(650 \mathrm{~nm})$ and infrared light $(940 \mathrm{~nm})$ via transmission. By the difference of optical 
density between the two wavelengths, the relative content of chlorophyll (SPAD value) can be obtained. For the measurement, three plants for each replicate in each accession and three leaves in the middle of each plant were selected, and each measurement was repeated three times.

\section{Statistical analysis}

Statistical analysis of basic data is carried out in Excel 365. Cluster analysis was performed based on the unweighted pair-group method with arithmetic means (UPGMA), using the SPSS for windows. The correlation analysis among the index values of these traits under stress was performed using Pearson's Correlation Coefficient using R studio software version 1.2.500.1.

\section{Results}

\section{Variation in salinity tolerance of garlic germplasm from salt injury observation}

Based on the performance of 354 garlic germplasm under salt stress, the SII of all tested germplasm under salt stress were calculated and distributed from 16.51 to 98.15. A cluster analysis based on the un-weighted pair group method assigned the 354 germplasm into five main groups. Group I represents two accessions of $8 \mathrm{~N} 327$ and 8N825, recognized as highly tolerance to salt stress with SII range from 16.51 to 17.59. Group II exhibits 24 germplasms, having the SII from 21.83 to 34.72 regarded as tolerance to salt stress. Group III illustrates 269 germplasm of moderately tolerance, which SII distributed from 35.45 to 57.01. Group IV covers 54 accessions recognized as susceptible to salt stress having the SII from 57.41 to 81.48 . Group V include 5 accessions with SII range of 91.53 to 98.15 known as highly susceptible to salt stress (Table 2; Figs. 1 and 2; Table Al in the Appendix).

Table 2. Classification of the germplasms on the base of SII

\begin{tabular}{c|c|c|c}
\hline Tolerance & Germplasm name & $\begin{array}{c}\text { No of } \\
\text { germplasm }\end{array}$ \\
\hline Highly tolerant & 8N327 8N825 & 2 \\
Tolerant & $\begin{array}{c}\text { 8N850 8N847 8N724 8N869 8N908 8N911 8N325 8N360 8N032 8N128 T-167 8N167 8N364 } \\
\text { T-141 8N141A 8N141B T-261 8N038A 8N719 8N261 T-17 T-258 8N026B 8N748 }\end{array}$ & 24 \\
& $\begin{array}{c}\text { 8N422 8N503 8N406 8N312 ZS-9 8N556 8N423 8N587 8N002 8N764 8N512 8N273 8N421 } \\
\text { Sensitive }\end{array}$ & $\begin{array}{c}\text { 8N560 8N930 8N514 JX-1 8N372 8N076 8N566 8N654 8N786 WQS 8N780 8N629 8N037 JX- } \\
\text { 8N427 8N332 8N561 8N675 8N526 8N950 8N030A 8N1040 8N545 8N760 8N559B 8N1046 }\end{array}$ & 54 \\
\hline Highly sensitive & 8N970 8N676 8N1042 & 5 \\
\hline
\end{tabular}

\section{Agronomic traits response of different garlic germplasm to salt stress}

$\mathrm{NaCl}$ salt stress decreased the growth performance of seedlings in most of 354 garlic germplasm to a different extent. The plant height showed a dispersing and great variation in the growth reduction of most germplasm under stress as compared to the control. Similarly, larger decreases in leaf length were observed under stress for most accessions. The leaf width and the ratio of healthy leaves number of germplasms also displayed a certain degree of difference between salt treatment and the control (Fig. 3). In more details, RPH varied from 0.42 to 1.00 with a mean of 0.73 and the frequencies 
of germplasm resources with different RPH values were almost normally distributed. Some germplasm such as 8N327 (0.87), 8N570 (0.93), 8N654 (0.94), 8N738 (0.95) T$167(0.96) 8 \mathrm{~N} 222(0.97)$ and T-17 (1.00) had the RPH value over 0.9, indicating these germplasms were more salt tolerant than other germplasm based on plant height reduction. Lower RPHs was found in 8N830 (0.47), 8N808 (0.44), 8N675 (0.44), etc., indicating these germplasms were highly susceptible to salt stress based on plant height reduction (Fig. 4a). RLL values ranged between 0.41 and 0.97 with a mean of 0.64 and the frequencies of germplasm resources with different RLL values were also nearly normally distributed. T-258 (0.89), 8N424(0.91), 8N239 (0.92), 8N992 (0.96) and 8N069 (0.97) had higher RLL values, indicating that they were salt-tolerant based on leaf length change; whereas, 8N586(0.45), 8N888 (0.44), MS No1 (0.44) 8N643 (0.43), and 8 N1008(0.43) were highly susceptible to salt stress (Fig. 4b). RLW values varied from 0.43 to 1.00 with a mean of 0.86 and the frequency distribution of germplasm resources with different RLW values was skewed, indicating the leaf width of most accessions was relatively stable under salt stress. Higher relative values of leaf width were recorded for T-17 (0.86), 8N826 (0.87), 8N032 (0.93), 8N325 (0.96), T-141 (0.97) $8 \mathrm{~N} 847$ (0.99), 8N519 (0.97), and 8N078B (1.00). Lower RLWs were found for 8N780 (0.43), 8N953 (0.49), 8N1005 (0.50) and 8N1022 (0.50) (Fig. 4c). RRHL values ranged between 0.71 and 0.99 , within a mean of 0.88 and the frequencies of germplasm resources with different RRHL values were normally distributed. 8N758 (0.91), 8N249, (0.92), 8N876 (0.93), 8N808 (0.94), 8N066 (0.95), 8N922 (0.96), 8N1005 (0.97), $8 \mathrm{~N} 1004(0.98), 8 \mathrm{~N} 126(0.99)$ had the higher RRHL, indicating that these germplasms were more tolerant to salt based on RHL reduction than other germplasm. Lower RRHLs values were found for 8N586 (0.71), 8N675 (0.75) and 8N676 (0.75), showing that these germplasms are more susceptible to salt stress based on the RHL reduction (Fig. 4d). From the results above, it is obvious that the seedling growth of most accessions was decreased to different extent in the four parameters. However, the tolerance performance of different germplasm affected by salt stress is different in various agronomical traits. The SII for each accession is a comprehensive index, which is contributed by different single traits in different ways.

\section{Correlation among agronomic and physiological traits affected by salt stress}

By using 81 accessions as a pilot study, correlation analysis exhibited the association among different agronomic traits and physiological traits of garlic germplasm (Fig. 5). SII as an important comprehensive agronomic trait is extremely significantly negative correlated with PH $(r=-0.65)$, LL $(r=-0.64)$, LW $(r=-0.53)$, RHL $(r=-0.53)$, gs $(r=-$ $0.29), \mathrm{A}(\mathrm{r}=-0.44)$ and $\mathrm{E}(\mathrm{r}=-0.60)$ at $P_{0.001}$, highly significant with $\mathrm{Ch}(\mathrm{r}=-0.20)$ at $P_{0.05}$. Among other morphological and physiological traits, $\mathrm{PH}$ is extremely significant positive correlated with LL $(r=0.76)$, LW $(r=0.66)$, RHL $(r=0.47)$, A $(r=0.42), E$ ( $\mathrm{r}=0.50)$ at $P_{0.001}$ and highly significant positive with gs $(\mathrm{r}=0.25)$ at $P_{0.05}$. LL is extremely significantly positive related with $\mathrm{PH}, \mathrm{LW}, \mathrm{RHL}, \mathrm{A}, \mathrm{E}$ and $\mathrm{Ch}$ at $P_{0.001}$. LW is highly significantly positive with RHL, A and $\mathrm{E}$ at $P_{0.05}$ except for the relationship with PH and LL. RHL is also extremely significantly positive related with A $(r=0.50)$, $\mathrm{E}(\mathrm{r}=0.64)$ and $\mathrm{Ch}(\mathrm{r}=0.48) . \mathrm{Ci}$ is extremely significantly positive with $\mathrm{gs}(\mathrm{r}=0.41)$, $A(r=0.34)$ and $E(r=0.34)$. gs is extremely significantly positive with $A(r=0.35)$, $\mathrm{E}(\mathrm{r}=0.26)$ and $\mathrm{Ci}$. A is extremely significantly positive with $\mathrm{E}(\mathrm{r}=0.65), \mathrm{Ch}(\mathrm{r}=0.27)$ besides PH, LL, RHL, $\mathrm{Ci}$ and gs. $\mathrm{E}$ is extremely significantly positive with $\mathrm{Ch}(\mathrm{r}=0.37)$ LL.RHL and A. 


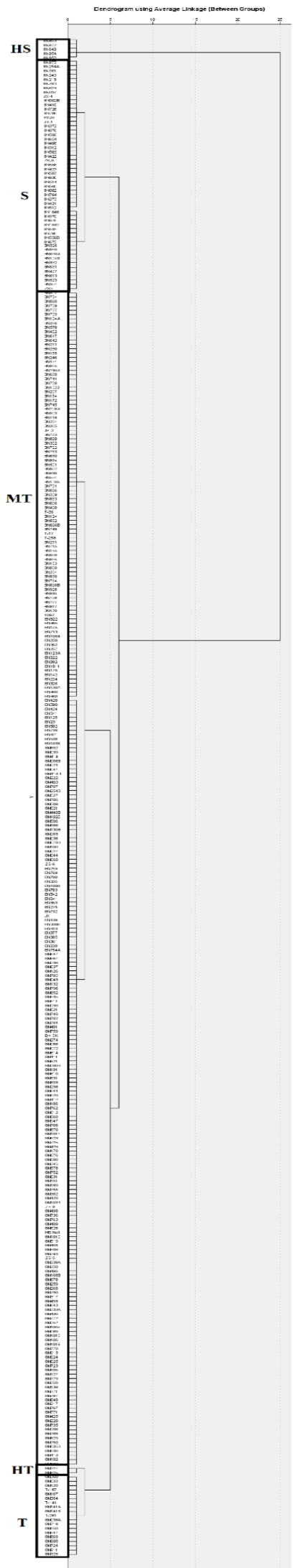

Figure 1. Cluster analysis of the garlic germplasm based on the salt injury index (SII) using unweighted pair-group method (UPGMA)

APPLIED ECOLOGY AND ENVIRONMENTAL RESEARCH 19(3):2281-2303.

http://www.aloki.hu • ISSN 15891623 (Print) • ISSN 17850037 (Online)

DOI: http://dx.doi.org/10.15666/aeer/1903_22812303

(c) 2021, ALÖKI Kft., Budapest, Hungary 


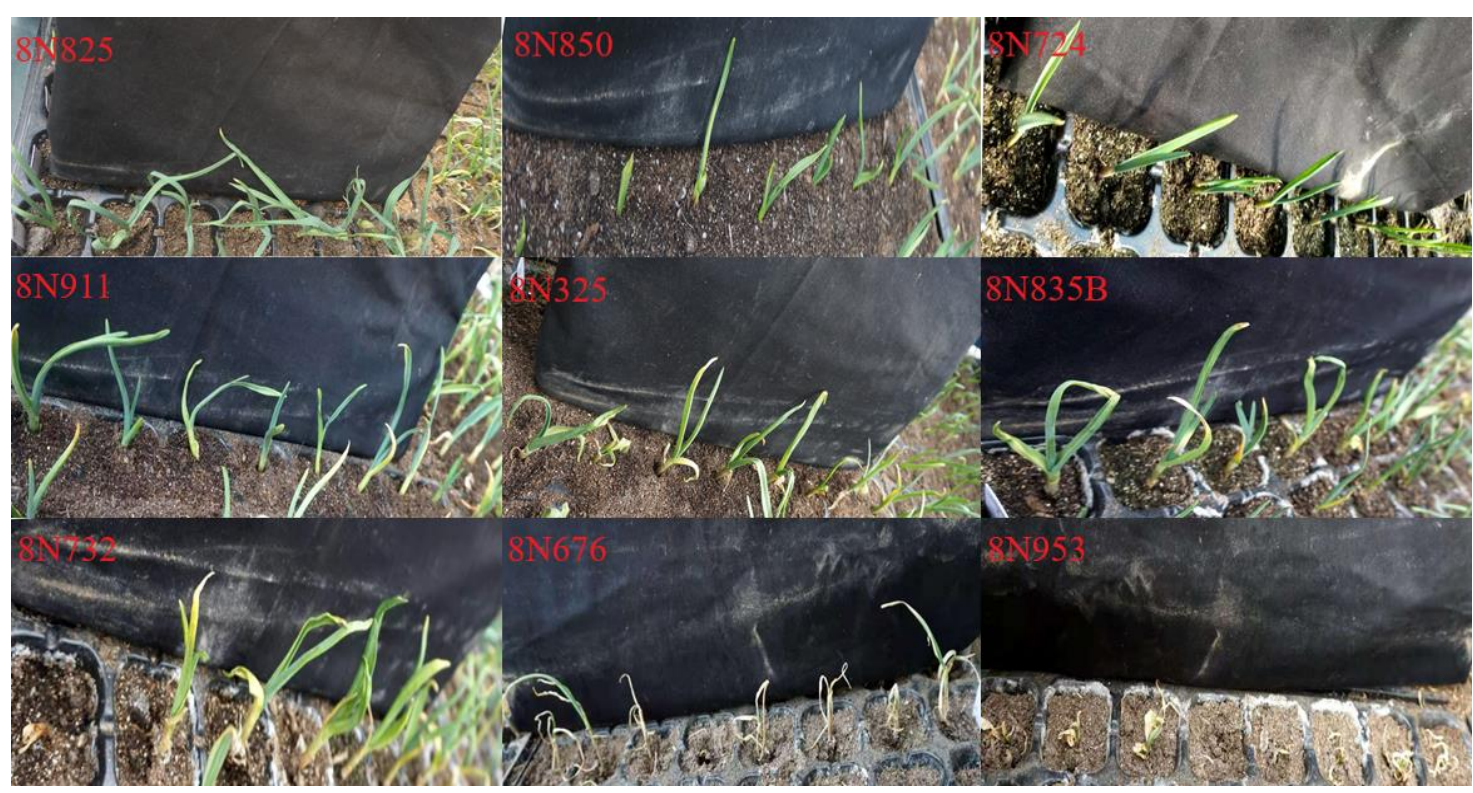

Figure 2. Growth performance of representative germplasm with different tolerance to salt stress
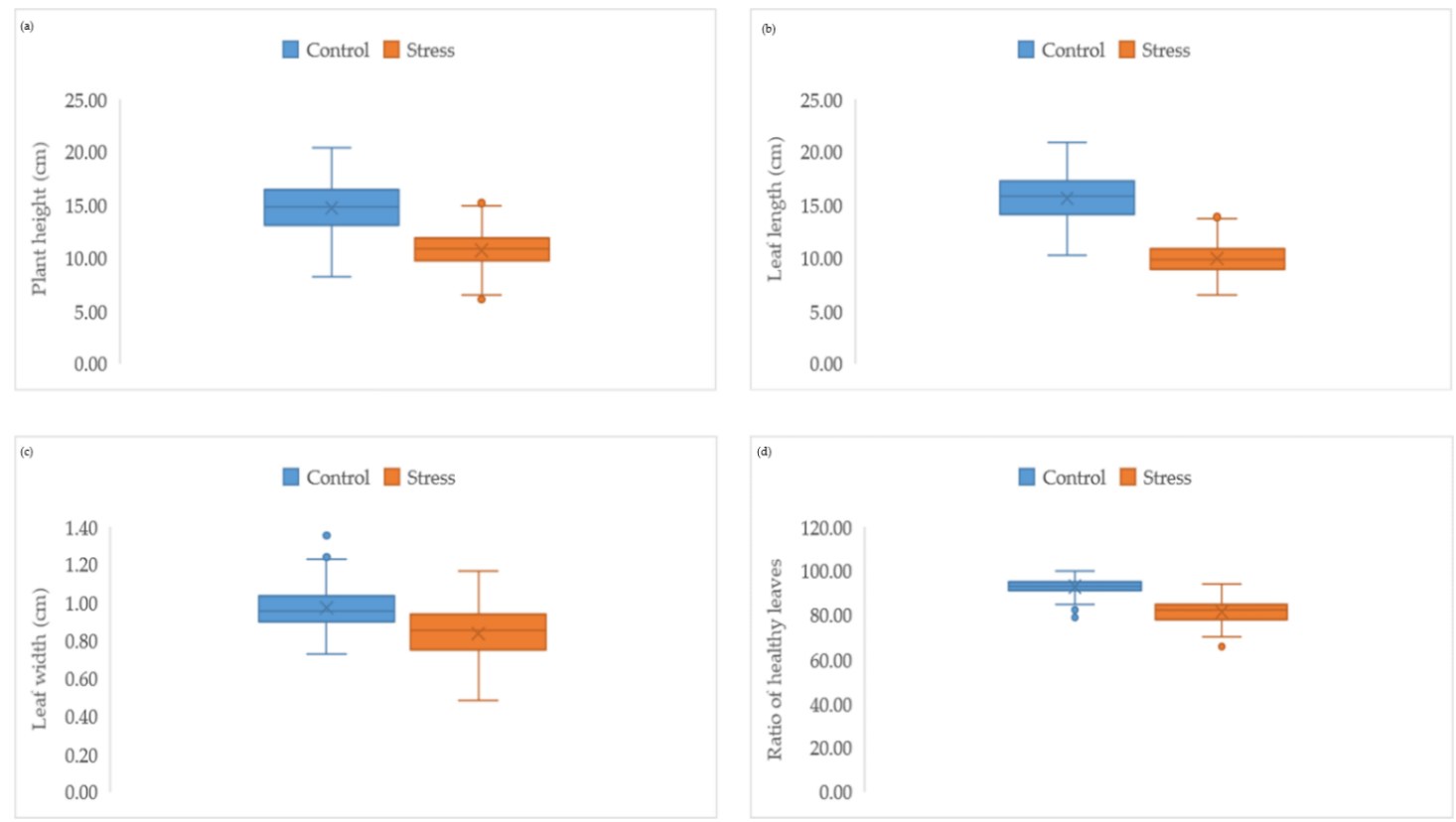

Figure 3. The value distribution and comparison of agronomic traits of all garlic germplasm under salt stress and under control. (a) Plant height (cm); (b) leaf length (cm); (c) leaf width $(\mathrm{cm}) ;(d)$ ratio of healthy leaves

\section{Discussion}

Tolerance to salt is important target trait for garlic breeding. Reasonable identification method is the basis of successful salt tolerance evaluation of garlic germplasm or breeding materials. Mass screening for salt tolerance of crops is complex, even in the soil culture or directly in the field because of multiplicity limitations like the 
status of soil fertility, irrigation management (Perez-Harguindeguy et al., 2016), salinity type (Munns and Tester, 2008) meteorological aspects like temperature and humidity) and as well as natural variation in fields (Hasana and Miyake, 2017). Field screening techniques have been reported confronting the main problem of soil heterogeneity, and a limited number of genotypes could be handled (Aslam et al., 1993).

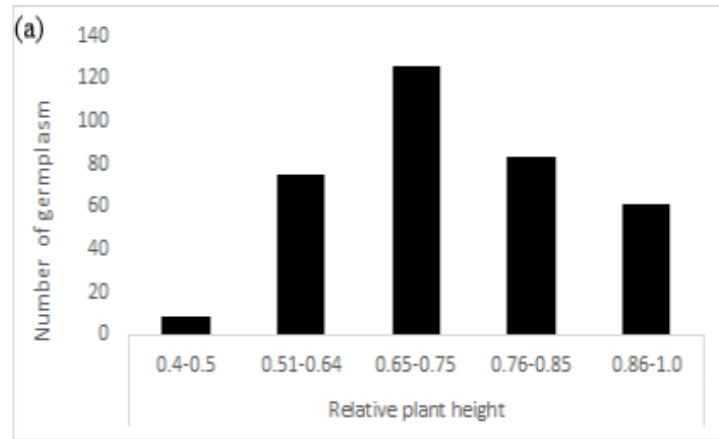

(c)
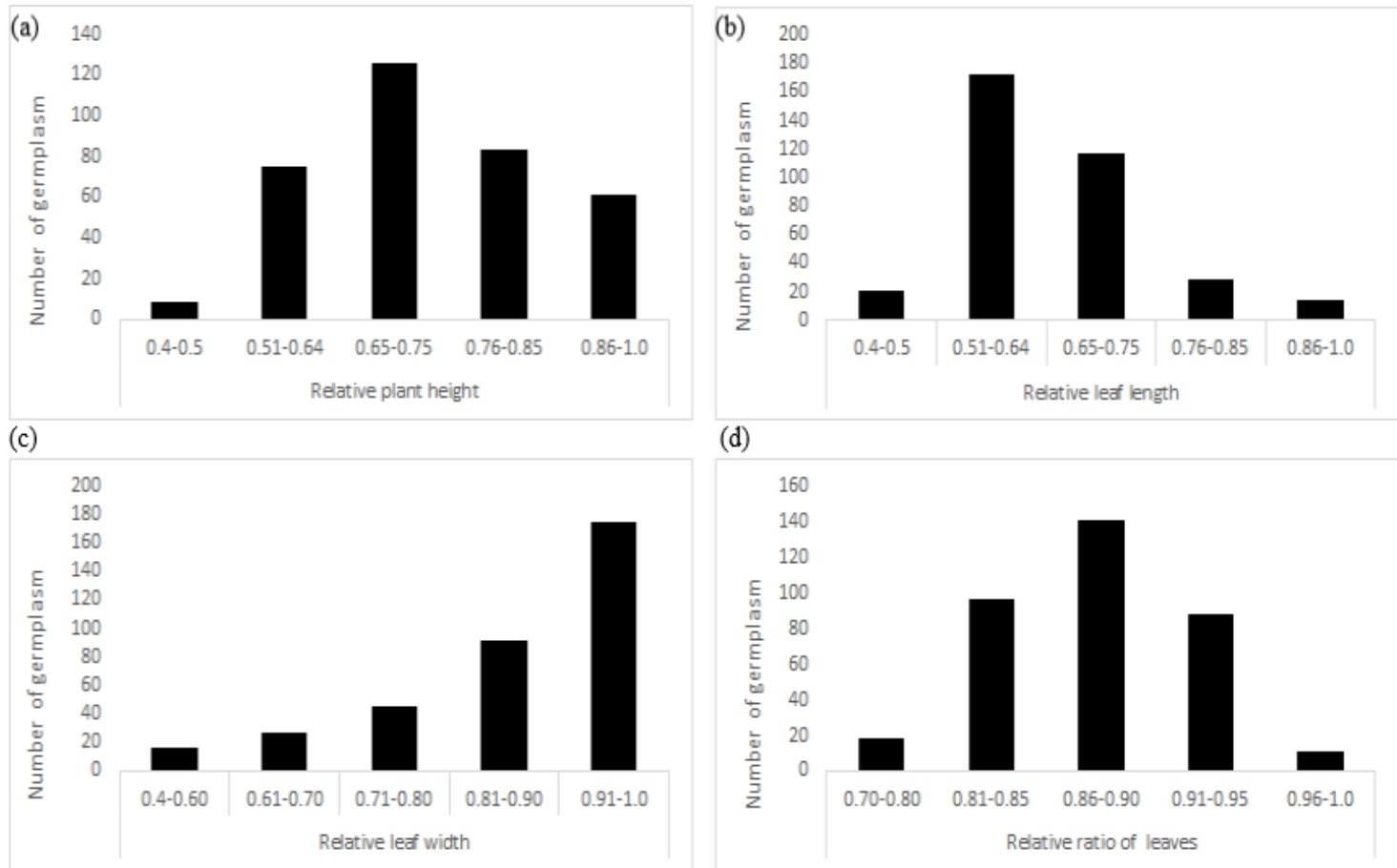

(d)

Figure 4. Germplasm frequency distribution in different relative value range of each growth parameters under salt stress to under control. (a) Relative plant height; (b) relative leaf length; (c) relative leaf width; (d) relative ratio of leaves

In the present study, we designed a pot culture method to characterize saline tolerance of garlic germplasm at the seedling stage. We screened out two highly tolerant and 24 tolerant garlic germplasm which are valuable for breeding and further study. The SII from visual salt injury observation is a comprehensive performance of plants under salt stress. It is reflected in many aspects of plant growth. The method is rapid and economical, and can easily meet the experimental conditions with the following advantages: (i) the salinity is standardized in the pot, or among pots, (ii) the irrigations quantity could be controlled, (iii) problems associated with salt depletion have been overcome. The effectiveness of this method was also confirmed by previous study in other crops such as rice (Kakar et al., 2019) and cotton (Sikder et al., 2020).

A reliable technical standard and index system for salt injury grading and tolerance classification is also a key to successfully develop a target-specific variety for salt tolerance. Visual symptoms of salt stress are mainly chlorosis of leaves, leaf tips burning, plant stunted growth and wilting (IRRI, 2014), and visual salt injury grades in rice. Sabra et al. (2012) studied the salt injury in three different Echinacea species by observing the appearance of leaves to develop a five-point scale according to the severity of necrotic tissues and number of injured plants. In the present study, we successfully distinguished garlic germplasm with the extensively distribution of SII 
value from 16.51 to 98.15 based on the modified grading standard of visual salt injury of leaves and plants in garlic (Table 1). For the salt tolerance evaluation, we did not use directly the arbitrary man-made resistance grading standard as in previous studies (Kopittke et al., 2009; Bolton and Simon, 2019). By the aid of cluster analysis based on the SII of each germplasm, we divided all germplasm into five groups, which exhibits high homogeneity within a cluster and high heterogeneity between clusters and help to setup a reasonable salt tolerance classification system according with the actual tolerance distribution in garlic and some other crop (Pradheeban et al., 2015).

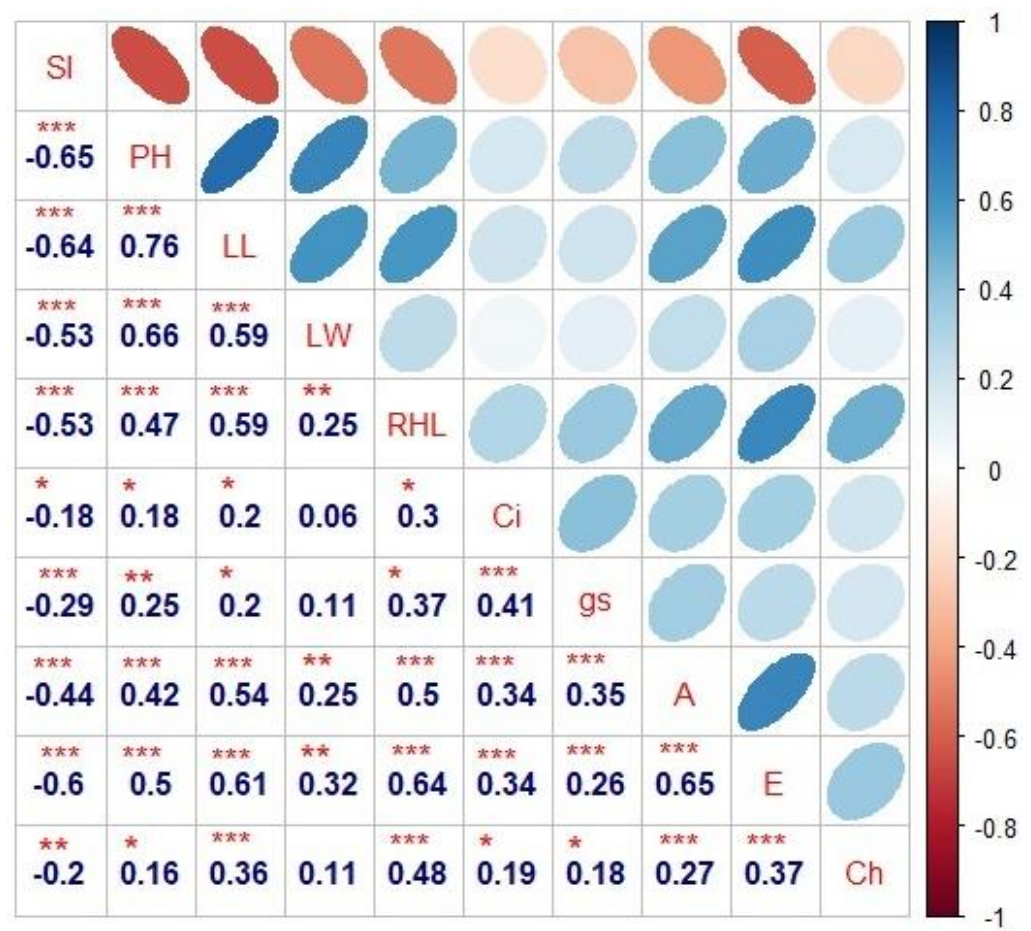

Figure 5. Correlation coefficients among the growth attributes of garlic. The upper diagonal represents the correlation coefficient with significance levels at $*_{p}<0.05, * *<0.01$, and *** $p<0.001$, respectively; PH (plant height), LL (leaf length), LW (leaf width), RHL (Ratio of healthy leaves) $\mathrm{Ci}$ (Substomatal $\mathrm{CO}_{2}$ concentration), gs (Stomatal Conductance), A (Respiration), E(Transpiration), Ch (Chlorophyll content)

Salt stress reduces plant growth and productivity by affecting morphological, anatomical, biochemical and physiological characteristics, processes and functions. Reduced plant height and other morphological characters are the most distinct and obvious effect of salt stress. Depressed growth due to salinity is attributed to several factors such as, water stress specific ion toxicity and ion imbalance stress or induced nutritional deficiency. Our findings show that, plant height of all the germplasms deceased by the salinity stress. The reduced plant height might be attributed to the direct effect of excess salt on plant tissues and poor intake of minerals. Reduced plant height under saline conditions has been observed in garlic (Shama et al., 2016) and quinoa (Cai and Gao, 2020).

Leaf area represents the plant growth measurement (leaf length and width), which can be affected by salt stress. Our results showed a decrease in leaf length and width with $\mathrm{NaCl}$ stress. These results agree with Mathur et al. (2006); they reported that the 
moth bean plant (Vigna aconitifolia L.) with increasing concentration of sodium chloride, led to a decrease in leaf area. This reduction was inversely proportional to the concentration of $\mathrm{NaCl}$. Also, a significant decrease in leaf area of sugar cane (Beta vulgaris L.) in response to salt stress using concentration zero, 50, 100, $150 \mathrm{mmol}$ of sodium chloride, has been reported (Jamil et al., 2007). Other supporting results include those of Zhao et al. (2007), with their study on oat (Avena sativa L.) Yilmaz and Kina (2008), with their study on Fragaria x anassa (L.).

$\mathrm{NaCl}$ salt stress decrease ratio of healthy number of leaves in plants, compared with the control plant. The results have been confirmed by the results of Karen et al. (2002), with their study on Cirer arietinum L. and Lopez et al. (2003), with their study on the teprary bean (Phaseolus acutifolius L.), cowpea (Vigna unguiculata L.), and wild bean (Phaseolus filiformis L). They mentioned that, the treatment of $\mathrm{NaCl}$ reduced the number of leaves compared with control plants. Shama et al. (2016) reported that saline water irrigation significantly decreased the number of leaves and plant height of garlic. The decrease of leaves number may be due to the accumulation of $\mathrm{NaCl}$ in the cell wall and cytoplasm of the leaves. At the same time, their vacuole sap cannot accumulate more salts and, thereby decreases the concentration of salt inside the cells, which ultimately leads to their quick death (Munns, 2002).

Salinity tolerance has been measured based on both the absolute and relative values of plant growth, which are very important in assessing plant material of diverse origin (Ashraf and Waheed, 1990; Ding et al., 2018). The 354 accessions here were assessed for their ability to sustain growth under saline conditions, as absolute values under stress and relative values compared with control. These results were in line with other previous studies that salinity suppressed agronomic traits in Triticum durum Desf (Noori and McNeilly, 2000) and sweet sorghum (Ding et al., 2018).

From the correlation analysis, although some correlation coefficients were not very high, they were significant. This is mainly because of the large-scale samples, some of which may contribute interference to the final result. The reliability of the weaker correlation results from large-scale at an enhanced significance criterion of $P_{0.001}$ besides $P_{0.01}$ and $P_{0.05}$ are equally recognized as the strong correlation in small samples (Abdelghany et al., 2020; Azam et al., 2021). SII as a comprehensive index are involved in many aspects of plants which may be affected and interacted with each other. In our study, among indexes of the observed agronomic traits at seedling stage, it was found that SII was extremely significantly negative correlated with all the measured agronomic traits under stress, and that there was also extremely significantly negative correlation between the physiological traits affected by salt stress, which provides important clue to assess the plant response to salt stress. These findings are consistent with the previous study in pistachio (Karimi and Roosta, 2014).

$\mathrm{NaCl}$ stress can decrease in physiological activities and consequently hinder the photosynthetic mechanism of the plant (Khan, 2016). In the current study, $\mathrm{NaCl}$ stress is a negative correlation with physiological traits such as sub-stomatal $\mathrm{CO}_{2}$ concentration (ci), stomatal conductance (gs), transpiration (A), respiration (E), and relative chlorophyll content $(\mathrm{Ch})$. Generally, $\mathrm{CO}_{2}$ exchange was regarded as an important indicator of the growth of plant, because of its direct link to net productivity (Asharf, 2004). It was proven that sub-stomatal $\mathrm{CO}_{2}$, stomatal conductance, transpiration and rate of photosynthesis of all the parameters are affected by salt stress. These results agree with previously report in rocket (Eruca sativa (L.) Mill.), where there were negative correlation between salinity and gas exchange parameters (Hniličková et al., 
2017). The decrease in gaseous exchange attributes in the current study might be associated with salinity-induced osmotic stress that rendered the growing plants out of the water and hampered the rate of transpiration, which further excavated water and $\mathrm{CO}_{2}$ supply for normal photosynthesis (Shahzad et al., 2019). They might also be due to osmotic and hormonal imbalances created by the generation of reactive oxygen species (ROS) in plant cells that impaired carbohydrates metabolism and hence the photosynthetic efficiency (Bergmann et al., 2008).

The impact of photosynthesis can be evaluated from the photosynthetic pigments. With increasing salt stress, the SPAD value decreased. Previous studies have described that salinity stress declined photosynthetic pigments of plants (Anand and Byju, 2008) and have also shown that the SPAD value measured by the SPAD chlorophyll meter is highly correlated with chlorophyll content (Anand and Byju, 2008). In the present study the chlorophyll content are negative correlation with salt stress. It was reported that the effect of salt stress on chlorophyll was varied species to species, and some studies have shown that salt stress can inhibit the chlorophyll synthesis of plants (Wang et al., 2015). Heidari (2012) reported that salt stress is a negative correlation with chlorophyll content in ocium basilicum (L.). Gouveianeto et al. (2011) found the main reason for the decrease in chlorophyll content caused by high salt concentration was the blocking of electron transport.

\section{Conclusions}

This study revealed a widely variation of salt tolerance during the seedling stage in a collection of diverse garlic germplasms based on an improved identification method and evaluation system. The discovery of salt tolerant accessions could not only serve as potential materials for identification of salt tolerant associated QTLs/genes, but also were promising for breeders to develop salt-tolerant cultivars. Although the respective agronomic traits of different germplasm had somewhat different response to salt stress, there were significantly or extremely significantly positive correlation among the most concerned agronomic and physiological traits affected by salt stress and the significantly or extremely significantly negative relationship between SII and morphological traits (PH, LL, LW, RHL), also between SII and physiological traits (gs, A, E, Ch) under stress. All these results provide the valuable base for the establishment of the reasonable salt-tolerance identification and classification standards and technical index, and further salt tolerance mechanism study.

Acknowledgements. This work was supported by grants from the China Agriculture Research System (CARS-24-A-01), Science and Technology Innovation Program of the Chinese Academy of Agricultural Sciences (CAAS-ASTIP-2019-IVFCAAS), National Crop Germplasm Resources Infrastructure in China (NICGR2019-15).

Conflict of interests. The authors declare no conflict of interests.

\section{REFERENCES}

[1] Abdelghany, A. M., Zhang, S., Azam, M., Shaibu, A. S., Feng, Y., Li, Y., Tian, Y., Hong, H., Li, B., Sun, J. (2020): Profiling of seed fatty acid composition in 1025 Chinese soybean accessions from diverse ecoregions. - The Crop Journal 8(4): 635-644. 
[2] Acosta-Motos, J. R., Ortuño, M. F., Bernal-Vicente, A., Diaz-Vivancos, P., SanchezBlanco, M. J., Hernandez, J. A. (2017): Plant responses to salt stress: adaptive mechanisms. - Agronomy 7(1): 18.

[3] Alom, R., Hasan, M. A., Islam M. R., Wang, Q. F. (2016): Germination characters and early seedling growth of wheat (Triticum aestivum L.) genotypes under salt stress conditions. - Journal of Crop Science and Biotechnology 19(5): 383-392.

[4] Anand, M. H., Byju, G. (2008): Chlorophyll meter and leaf colour chart to estimate chlorophyll content, leaf colour, and yield of cassava. - Photosynthetica 46(4): 511516.

[5] Ashraf, M. (2004): Some important physiological selection criteria for salt tolerance in plants. Flora-Morphology, Distribution. - Functional Ecology of Plants 199(5): 361376.

[6] Ashraf, M., Waheed, A. (1990): Screening of local/exotic accessions of lentil (Lens culinaris Medic.) for salt tolerance at two growth stages. - Plant and Soil128(2): 167176.

[7] Aslam, M., Qureshi, R. H., Ahmed, N. (1993): A rapid screening technique for salt tolerance in rice (Oryza sativa L.). - Plant and Soil 150(1): 99-107.

[8] Azam, M., Zhang, S., Qi, J., Abdelghany, A. M., Shaibu, A. S., Ghosh, S., Feng, Y., Huai, Y., Gebregziabher, B. S., Li, J., Li, B. (2021): Profiling and associations of seed nutritional characteristics in Chinese and USA soybean cultivars. - Journal of Food Composition and Analysis 98: 103803.

[9] Bergmann, I., Geiß-Brunschweiger, U., Hagemann, M., Schoor, A. (2008): Salinity tolerance of the chlorophyll b-synthesizing cyanobacterium Prochlorothrix hollandica strain SAG 10.89. - Microbial ecology 55(4): 685-696.

[10] Bhutta, M. N., Smedema, L. K. (2007): One hundred years of waterlogging and salinity control in the Indus valley, Pakistan: a historical review. - Irrigation and Drainage The Journal of the International Commission on Irrigation and Drainage 56(1): 81-90.

[11] Blum, A. 2018: Plant Breeding for Stress Environments. - CRC Press, Boca Raton, FL.

[12] Bolton, A., Simon, P. (2019): Variation for salinity tolerance during seed germination in diverse carrot (Daucus carota L.) germplasm. - HortScience 54(1): 38-44.

[13] Cai, Z. Q., Gao, Q. (2020): Comparative physiological and biochemical mechanisms of salt tolerance in five contrasting highland quinoa cultivars. - BMC Plant Biology 20(1): $1-15$.

[14] Cocks, P. S. (2001): Ecology of herbaceous perennial legumes: a review of characteristics that may provide management options for the control of salinity and waterlogging in dryland cropping systems. - Australian Journal of Agricultural Research 52(2): 137-151.

[15] Crescimanno, G., Garofalo, P. (2006): Management of irrigation with saline water in cracking clay soils. - Soil Science Society of America Journal 70(5): 1774-1787.

[16] Ding, T., Yang, Z., Wei, X., Yuan, F., Yin, S., Wang, B. (2018): Evaluation of salttolerant germplasm and screening of the salt-tolerance traits of sweet sorghum in the germination stage. - Functional Plant Biology 45(10): 1073-1081.

[17] Francois, L. E. (1994): Yield and quality response of salt-stressed garlic. - HortScience 29(11): 1314-1317.

[18] Garrote- Moreno, A., McDonald, A., Sherman, T. D., Sanchez Lizaso, J. L., Heck Jr, K. L., Cebrian, J. (2015): Short-term impact of salinity pulses on ionic ratios of the seagrasses Thalassia testudinmu and Halodule wrightii. - Aquatic Botany 120: 315321.

[19] Gouveia-Neto, A. S., Silva Jr, E. A., Oliveira, R. A., Cunha, P. C., Costa, E. B., Câmara, T. J., Willadino, L. G. (2011): Water deficit and salt stress diagnosis through LED induced chlorophyll fluorescence analysis in Jatropha curcas L. oil plants for biodiesel. In Imaging, manipulation, and analysis of biomolecules, cells, and tissues. International Society for Optics and Photonics IX: 7902: 79020. 
[20] Gupta, B., Huang, B. (2014): Mechanism of salinity tolerance in plants: physiological, biochemical, and molecular characterization. - International Journal of Genomics.

[21] Hasana, R., Miyake, H. (2017): Salinity stress alters nutrient uptake and causes the damage of root and leaf anatomy in maize. - KnE Life Sciences 3(4): 219.

[22] Hasegawa, P. M. (2013): Sodium $\left(\mathrm{Na}^{+}\right)$homeostasis and salt tolerance of plants. Environmental and Experimental Botany 92: 19-31.

[23] Heidari, M. (2012): Effects of salinity stress on growth, chlorophyll content and osmotic components of two basil (Ocimum basilicum L.) genotypes. - African Journal of Biotechnology 11(2): 379-384.

[24] Hniličková, H., Hnilička, F., Martinkova, J., Kraus, K. (2017): Effects of salt stress on water status, photosynthesis and chlorophyll fluorescence of rocket. - Plant, Soil and Environment 63(8): 362-367.

[25] Hoque, M. M. I., Jun, Z., Guoying, W. (2015): Evaluation of salinity tolerance in maize (Zea mays L.) genotypes at seedling stage. - Journal of Bio Science \& Biotechnology 4(1): 39-49.

[26] International Rice Research institute. (2014): Standard evaluation system for rice (SES), - 5th edn. Los Banos ,Philippines.

[27] Jamil, M., Lee, K. B., Jung, K. Y., Lee, D. B., Han, M. S., Rha, E. S. (2007): Salt stress inhibits germination and early seedling growth in cabbage (Brassica oleracea capitata L.). - Pakistan Journal of Biological Sciences 10(6): 910-914.

[28] Kakar, N., Jumaa, S. H., Redoña, E. D., Warburton, M. L., Reddy, K. R. (2019): Evaluating rice for salinity using pot-culture provides a systematic tolerance assessment at the seedling stage. - Rice 12(1): 1-14.

[29] Karen, W., Anthony, R. Y., Timothy, J. F. (2002): Effect of salinity and ozone, indivdually and in combination on growth and ion contents of two chickpea (Cicer aritinum L.) varieties. - Environmental Pollution 120(2): 397-403.

[30] Karimi, H. R., Roosta, H. R. (2014): Evaluation of inter-specific hybrid of P. atlantica and P. vera L. cv. 'Badami-Riz-e-Zarand' as pistachio rootstock to salinity stress according to some growth indices and eco-physiological and biochemical parameters. Journal of Stress Physiology \& Biochemistry 10(3): 5-17.

[31] Khan, M. N. (2016): Growth and physiological attributes of tomato (Lycopersicon esculentum Mill.) genotypes as affected by $\mathrm{NaCl}$ stress. - American Journal of Plant Sciences 7(3): 453-460.

[32] Kopittke, P. M., Kopittke, R. A., Menzies, N. W. (2009): Measurement and interpretation of salinity tolerance in four perennial grasses. - Journal of Plant Nutrition 32(1): 30-43.

[33] López-Aguilar, R., Orduño-Cruz, A., Lucero-Arce, A., Murillo-Amador, B., TroyoDiéguez, E. (2003): Response to salinity of three grain legumes for potential cultivation in arid areas. - Soil science and plant nutrition 49(3): 329-336.

[34] Machado, R. M. A., Serralheiro, R. P. (2017): Soil salinity: effect on vegetable crop growth. Management practices to prevent and mitigate soil salinization. - Horticulturae 3(2): 30 .

[35] Mateo-Sagasta, J., Burke, J. (2011): Agriculture and water quality interactions: a global overview. - SOLAW Background Thematic Report-TR08 46.

[36] Mathur, N., Singh, J., Bohra, A., Vyas, A. (2006): Biomass production, productivity and physiological changes in moth bean genotypes at different salinity level. American Journal of Plant Physiol 1(2): 210-213.

[37] Munns, R. (2002): Comparative physiology of salt and water stress. - Plant, Cell and Environment 25(2): 239-250.

[38] Munns, R., Tester, M. (2008): Mechanisms of salinity tolerance. - Annual Reviews Plant Biol. 59: 651-681. 
[39] Nasri, N., Saïdi, I., Kaddour, R., Lachaâl, M. (2015): Effect of salinity on germination, seedling growth and acid phosphatase activity in lettuce. - American Journal of Plant Sciences 6(01): 57-63.

[40] Noori, S. S., McNeilly, T. (2000): Assessment of variability in salt tolerance based on seedling growth in Triticum durum Desf. - Genetic Resources and Crop Evolution 47(3): 285-291.

[41] Perez-Harguindeguy, N., Diaz, S., Garnier, E., Lavorel, S., Poorter, H., Jaureguiberry, P., Bret-Harte, M. S., Cornwell, W. K., Craine, J. M., Gurvich, D. E., Urcelay, C. (2016): Corrigendum to: new handbook for standardised measurement of plant functional traits worldwide. - Australian Journal of Botany 64(8): 715-716.

[42] Pradheeban, L., Nissanka, N. A. A. S. P., Suriyagoda, L. D. B. (2015): Clustering of Rice (Oryza sativa L.) Varieties cultivated in Jaffna District of Sri Lanka based on salt tolerance during germination and seedling stages. - Tropical Agricultural Research 25(3): 358-375.

[43] Ritzema, H. P. (2016): Drain for gain: managing salinity in irrigated lands. Agricultural Water Management 176: 18-28.

[44] Sabra, A., Daayf, F., Renault, S. (2012): Differential physiological and biochemical responses of three Echinacea species to salinity stress. - Scientia Horticulturae 135: 2331.

[45] Shahbaz, M., Ashraf, M., Al-Qurainy, F., Harris, P. J. (2012): Salt tolerance in selected vegetable crops. - Critical Reviews in Plant Sciences 31(4): 303-320.

[46] Shahzad, H., Ullah, S., Iqbal, M., Bilal, H. M., Shah, G. M., Ahmad, S., Zakir, A., Ditta, A., Farooqi, M. A., Ahmad, I. (2019): Salinity types and level-based effects on the growth, physiology and nutrient contents of maize (Zea mays). - Italian Journal of Agronomy 14(4): 199-207.

[47] Shama, M. A., Moussa, S. A., El Fadel, N. A. (2016): Salicylic acid efficacy on resistance of garlic plants (Allium sativum, L.) to water salinity stress on growth, yield and its quality. - Alexandria. Science Exchange Journal 37(2): 165-174.

[48] Sikder, R. K., Wang, X., Jin, D., Zhang, H., Gui, H., Dong, Q., Pang, N., Zhang, X and Song, M. (2020): Screening and evaluation of reliable traits of upland cotton (Gossypium hirsutum L.) genotypes for salt tolerance at the seedling growth stage. Journal of Cotton Research 3: 1-13.

[49] Tanveer, K., Gilani, S., Hussain, Z., Ishaq, R., Adeel, M., Ilyas, N. (2020): Effect of salt stress on tomato plant and the role of calcium. - Journal of Plant Nutrition 43(1): 28-35.

[50] Teshika, J. D., Zakariyyah, A. M., Zaynab, T., Zengin, G., Rengasamy, K. R., Pandian, S. K., Fawzi, M. M. (2019): Traditional and modern uses of onion bulb (Allium cepa L.): a systematic review. - Critical Reviews in Food Science and Nutrition 59(1): 39-70.

[51] Uddin, M. S., Hossain, K. M. W. (2018): Screening of wheat genotypes against salinity at early vegetative stage in pot culture. - Bangladesh Journal of Botany 47(3): 381-387.

[52] Walbot, V., Cullis, C. A. (1985): Rapid genomic change in higher plants. - Annual Review of Plant Physiology 36(1): 367-396.

[53] Wang, X., Geng, S., Ma, Y., Shi, D., Yang, C., Wang, H. (2015): Growth, photosynthesis, solute accumulation, and ion balance of tomato plant under sodium-or potassium-salt stress and alkali stress. - Agronomy Journal 107(2): 651-661.

[54] Wichelns, D., Qadir, M. (2015): Achieving sustainable irrigation requires effective management of salts, soil salinity, and shallow groundwater. - Agricultural Water Management 157: 31-38.

[55] Yilmaz, H., Kina, A. (2008): The influence of $\mathrm{NaCl}$ salinity on some vegetative and chemical changes of strawberries (Fragaria $\mathrm{x}$ ananassa L.). - African Journal Biotechnology 7(18): 3299-3305.

[56] Zhao, Z., Ma, B. L., Ren, C. Z. (2007): Growth, gas exchange, chlorophyll fluorescence and ion content of naked oat in response to salinity. - Crop Science 47(1): 123-131. 


\section{APPENDIX}

Table A1. Germplasms origin and their classification on the base of salt tolerance

\begin{tabular}{|c|c|c|c|c|c|}
\hline Sr. No & Germplasms ID & SII & Group & Tolerance & Province/world \\
\hline 1. & $8 \mathrm{~N} 327$ & 16.51 & 1 & HT & Yunnan Province \\
\hline 2. & $8 \mathrm{~N} 825$ & 17.59 & 1 & HT & Tajikistan \\
\hline 3. & $8 \mathrm{~N} 850$ & 21.83 & 2 & $\mathrm{~T}$ & Washington, United States \\
\hline 4. & $8 \mathrm{~N} 847$ & 22.84 & 2 & $\mathrm{~T}$ & Washington, United States \\
\hline 5. & $8 \mathrm{~N} 724$ & 25.00 & 2 & $\mathrm{~T}$ & Pakistan \\
\hline 6. & $8 N 869$ & 25.28 & 2 & $\mathrm{~T}$ & Uzbekistan \\
\hline 7. & 8 N908 & 25.40 & 2 & $\mathrm{~T}$ & Washington, United States \\
\hline 8. & 8 N911 & 25.74 & 2 & $\mathrm{~T}$ & Washington, United States \\
\hline 9. & $8 \mathrm{~N} 325$ & 26.46 & 2 & $\mathrm{~T}$ & Yunnan Province \\
\hline 10. & $8 \mathrm{~N} 360$ & 28.70 & 2 & $\mathrm{~T}$ & Europe \\
\hline 11. & $8 \mathrm{~N} 032$ & 28.70 & 2 & $\mathrm{~T}$ & Shanghai \\
\hline 12. & $8 \mathrm{~N} 128$ & 29.31 & 2 & $\mathrm{~T}$ & Jiangsu Province \\
\hline 13. & $\mathrm{~T}-167$ & 29.38 & 2 & $\mathrm{~T}$ & Yunnan Province \\
\hline 14. & $8 \mathrm{~N} 167$ & 29.78 & 2 & $\mathrm{~T}$ & Yunnan Province \\
\hline 15. & $8 N 364$ & 29.89 & 2 & $\mathrm{~T}$ & Korea \\
\hline 16. & $\mathrm{~T}-141$ & 30.56 & 2 & $\mathrm{~T}$ & Shandong Province \\
\hline 17. & $8 \mathrm{~N} 141 \mathrm{~A}$ & 30.89 & 2 & $\mathrm{~T}$ & Shandong Province \\
\hline 18. & $8 \mathrm{~N} 141 \mathrm{~B}$ & 31.48 & 2 & $\mathrm{~T}$ & Shandong Province \\
\hline 19. & $\mathrm{~T}-261$ & 32.25 & 2 & $\mathrm{~T}$ & Jiangsu Province \\
\hline 20. & $8 \mathrm{~N} 038 \mathrm{~A}$ & 32.30 & 2 & $\mathrm{~T}$ & Shandong Province \\
\hline 21. & $8 \mathrm{~N} 719$ & 33.33 & 2 & $\mathrm{~T}$ & Former Serbia and Montenegro \\
\hline 22. & $8 \mathrm{~N} 261$ & 34.04 & 2 & $\mathrm{~T}$ & Jiangsu Province \\
\hline 23. & $\mathrm{~T}-17$ & 34.12 & 2 & $\mathrm{~T}$ & Jiangsu Province \\
\hline 24. & $\mathrm{~T}-258$ & 34.14 & 2 & $\mathrm{~T}$ & Jiangsu Province \\
\hline 25. & $8 \mathrm{~N} 026 \mathrm{~B}$ & 34.72 & 2 & $\mathrm{~T}$ & Washington United States \\
\hline 26. & 8 N748 & 34.72 & 2 & $\mathrm{~T}$ & Turkey \\
\hline 27. & $8 \mathrm{~N} 715$ & 35.45 & 3 & MT & Illinois, United States \\
\hline 28. & $8 \mathrm{~N} 195$ & 35.66 & 3 & MT & Jiangsu Province \\
\hline 29. & $8 \mathrm{~N} 183$ & 36.11 & 3 & MT & Hubei Province \\
\hline 30. & $8 N 899$ & 36.11 & 3 & MT & Washington United States \\
\hline 31. & 8 N655 & 36.11 & 3 & MT & North Macedonia \\
\hline 32. & $8 \mathrm{~N} 808$ & 36.42 & 3 & MT & Washington United States \\
\hline 33. & $8 \mathrm{~N} 826 \mathrm{~B}$ & 36.90 & 3 & MT & Washington, United State \\
\hline 34. & $8 \mathrm{~N} 928$ & 37.04 & 3 & MT & Viet Nam \\
\hline 35. & $8 \mathrm{~N} 234$ & 37.17 & 3 & MT & Hubei Province \\
\hline 36. & $8 \mathrm{~N} 830$ & 37.19 & 3 & MT & Washington, United State \\
\hline 37. & $8 N 714$ & 37.30 & 3 & MT & Washington, United States \\
\hline 38. & $8 \mathrm{~N} 822$ & 37.57 & 3 & MT & Sachsen-Anhalt, Germany \\
\hline 39. & $109 \mathrm{Z}$ & 37.66 & 3 & MT & Jiangsu Province \\
\hline 40. & 8 N777 & 37.70 & 3 & MT & Andalucía, Spain \\
\hline 41. & $8 \mathrm{~N} 817$ & 37.70 & 3 & MT & Slovenia \\
\hline 42. & $8 \mathrm{~N} 170$ & 37.74 & 3 & MT & Yunnan Province \\
\hline
\end{tabular}




\begin{tabular}{|c|c|c|c|c|c|}
\hline 43. & $8 \mathrm{~N} 865$ & 37.96 & 3 & MT & Bulgaria \\
\hline 44. & $8 \mathrm{~N} 145$ & 38.10 & 3 & MT & Sichuan Province \\
\hline 45. & $8 \mathrm{~N} 845$ & 38.40 & 3 & MT & Washington, United State \\
\hline 46. & 8 N776 & 38.43 & 3 & MT & Andalucía, Spain \\
\hline 47. & $8 \mathrm{~N} 713$ & 38.89 & 3 & MT & California, United States \\
\hline 48. & 8N1004 & 38.89 & 3 & MT & Jiangsu Province \\
\hline 49. & $8 \mathrm{~N} 992$ & 39.05 & 3 & MT & Jiangsu Province \\
\hline 50. & $8 \mathrm{~N} 123 \mathrm{~A}$ & 39.15 & 3 & MT & Jiangsu Province \\
\hline 51. & 8 N622 & 39.15 & 3 & MT & Shandong Province \\
\hline 52. & $8 \mathrm{~N} 257$ & 39.29 & 3 & MT & Jiangsu Province \\
\hline 53. & $8 \mathrm{~N} 258$ & 39.33 & 3 & MT & Jiangsu Province \\
\hline 54. & $8 \mathrm{~N} 862$ & 39.35 & 3 & MT & Jiangsu Province \\
\hline 55. & $8 \mathrm{~N} 860$ & 39.68 & 3 & MT & Korea, South \\
\hline 56. & $8 \mathrm{~N} 130 \mathrm{~A}$ & 39.81 & 3 & MT & Anhui Province \\
\hline 57. & $8 \mathrm{~N} 900$ & 39.90 & 3 & MT & Washington United States \\
\hline 58. & $8 \mathrm{~N} 326$ & 40.11 & 3 & MT & Yunnan Province \\
\hline 59. & 8N1011 & 40.21 & 3 & MT & Jiangsu Province \\
\hline 60. & $8 \mathrm{~N} 175$ & 40.21 & 3 & MT & Yunnan Province \\
\hline 61. & $8 \mathrm{~N} 142$ & 40.28 & 3 & MT & Shandong Province \\
\hline 62. & $8 \mathrm{~N} 224$ & 40.33 & 3 & MT & Shaanxi Province \\
\hline 63. & $8 \mathrm{~N} 1005$ & 40.74 & 3 & MT & Jiangsu Province \\
\hline 64. & $8 \mathrm{~N} 209$ & 40.74 & 3 & MT & Liaoning Province \\
\hline 65. & $8 N 781$ & 40.74 & 3 & MT & Washington United States \\
\hline 66. & $8 N 826$ & 40.74 & 3 & MT & Washington, United State \\
\hline 67. & $8 \mathrm{~N} 846$ & 40.74 & 3 & MT & Washington, United State \\
\hline 68. & $8 \mathrm{~N} 534$ & 40.74 & 3 & MT & Guizhou \\
\hline 69. & $8 N 863$ & 40.81 & 3 & MT & Italy \\
\hline 70. & $8 N 832$ & 41.01 & 3 & MT & Washington, United State \\
\hline 71. & $\mathrm{~T}-36$ & 41.08 & 3 & MT & Shandong Province \\
\hline 72. & $8 \mathrm{~N} 124$ & 41.09 & 3 & MT & Jiangsu Province \\
\hline 73. & 8N096 & 41.14 & 3 & MT & Gansu Province \\
\hline 74. & $8 \mathrm{~N} 490$ & 41.14 & 3 & MT & United States \\
\hline 75. & 8 N922 & 41.42 & 3 & MT & Yunnan Province \\
\hline 76. & $8 N 864$ & 41.62 & 3 & MT & Bulgaria \\
\hline 77. & $8 \mathrm{~N} 302$ & 41.67 & 3 & MT & Yunnan Province \\
\hline 78. & $8 \mathrm{~N} 660$ & 41.67 & 3 & MT & Turkey \\
\hline 79. & $8 N 722$ & 41.67 & 3 & MT & Chile \\
\hline 80. & $8 \mathrm{~N} 753$ & 41.67 & 3 & MT & Washington United States \\
\hline 81. & $8 N 773$ & 41.67 & 3 & MT & Andalucía, Spain \\
\hline 82. & $8 \mathrm{~N} 890$ & 41.67 & 3 & MT & Washington United States \\
\hline 83. & $8 \mathrm{~N} 501$ & 41.85 & 3 & MT & Egypt \\
\hline 84. & 8 N741 & 42.06 & 3 & MT & Washington United States \\
\hline 85. & $8 \mathrm{~N} 758$ & 42.06 & 3 & MT & Castilla-La Mancha, Spain \\
\hline 86. & $8 \mathrm{~N} 154$ & 42.15 & 3 & MT & Shandong Province \\
\hline 87. & $8 \mathrm{~N} 1022$ & 42.20 & 3 & MT & Shandong Province \\
\hline 88. & $8 \mathrm{~N} 207$ & 42.20 & 3 & MT & Hebei Province \\
\hline
\end{tabular}




\begin{tabular}{|c|c|c|c|c|c|}
\hline 89. & $8 \mathrm{~N} 240 \mathrm{~A}$ & 42.33 & 3 & MT & Jiangsu Province \\
\hline 90. & $8 \mathrm{~N} 668$ & 42.33 & 3 & MT & Brazil \\
\hline 91. & $8 N 365$ & 42.55 & 3 & MT & Korea \\
\hline 92. & 8N118 & 42.59 & 3 & MT & Shaanxi Province \\
\hline 93. & $8 \mathrm{~N} 264$ & 42.59 & 3 & MT & Shandong Province \\
\hline 94. & 8N206A & 42.59 & 3 & MT & Hebei Province \\
\hline 95. & 8 N903 & 42.59 & 3 & MT & Washington United States \\
\hline 96. & $8 \mathrm{~N} 172$ & 42.68 & 3 & MT & Yunnan Province \\
\hline 97. & $8 \mathrm{~N} 745$ & 42.72 & 3 & MT & Albania \\
\hline 98. & $\mathrm{JX}-3$ & 42.86 & 3 & MT & Shandong Province \\
\hline 99. & $8 \mathrm{~N} 898$ & 43.06 & 3 & MT & Washington, United States \\
\hline 100. & $8 \mathrm{~N} 507$ & 43.12 & 3 & MT & Jiangsu \\
\hline 101. & 8 N734 & 43.12 & 3 & MT & Andalucía, Spain \\
\hline 102. & 8 N789 & 43.21 & 3 & MT & Varna, Bulgaria \\
\hline 103. & $8 \mathrm{~N} 570$ & 43.34 & 3 & MT & Washington, United States \\
\hline 104. & 8N104A & 43.52 & 3 & MT & Shaanxi Province \\
\hline 105. & $8 N 366$ & 43.52 & 3 & MT & Korea \\
\hline 106. & 8 N737 & 43.52 & 3 & MT & Shumen, Bulgaria \\
\hline 107. & $8 N 799$ & 43.52 & 3 & MT & USA \\
\hline 108. & $8 \mathrm{~N} 855$ & 43.78 & 3 & MT & Washington, United States \\
\hline 109. & $8 \mathrm{~N} 246$ & 43.92 & 3 & MT & Yunnan Province \\
\hline 110. & $8 \mathrm{~N} 434$ & 43.98 & 3 & MT & Henan \\
\hline 111. & $8 \mathrm{~N} 155$ & 44.09 & 3 & MT & Shandong Province \\
\hline 112. & $8 \mathrm{~N} 211$ & 44.14 & 3 & MT & Ningxia \\
\hline 113. & $8 \mathrm{~N} 260$ & 44.14 & 3 & MT & Jiangsu Province \\
\hline 114. & $8 \mathrm{~N} 642$ & 44.44 & 3 & MT & Guizhou \\
\hline 115. & $8 \mathrm{~N} 402$ & 44.44 & 3 & MT & Hebei Province \\
\hline 116. & $8 \mathrm{~N} 617$ & 44.44 & 3 & MT & Shandong Province \\
\hline 117. & $8 \mathrm{~N} 252$ & 44.84 & 3 & MT & Yunnan Province \\
\hline 118. & $8 \mathrm{~N} 436$ & 44.91 & 3 & MT & Henan \\
\hline 119. & 8 N772 & 44.97 & 3 & MT & Andalucía, Spain \\
\hline 120. & 8N1007 & 45.22 & 3 & MT & Shandong Province \\
\hline 121. & 8 N069 & 45.24 & 3 & MT & Shaanxi Province \\
\hline 122. & 8N1019 & 45.37 & 3 & MT & Shandong Province \\
\hline 123. & 8 N778 & 45.37 & 3 & MT & Andalucía, Spain \\
\hline 124. & 8 N913 & 45.37 & 3 & MT & lead the United States \\
\hline 125. & 8N1016 & 45.37 & 3 & MT & Shandong Province \\
\hline 126. & 8 N106 & 45.37 & 3 & MT & Russia \\
\hline 127. & $8 \mathrm{~N} 924$ & 45.43 & 3 & MT & Guizhou Province \\
\hline 128. & $8 \mathrm{~N} 025$ & 45.50 & 3 & MT & Hubei Province \\
\hline 129. & $8 \mathrm{~N} 371$ & 45.74 & 3 & MT & Sichuan Province \\
\hline 130. & 8 N779 & 45.83 & 3 & MT & Andalucía, Spain \\
\hline 131. & $8 \mathrm{~N} 358$ & 45.86 & 3 & MT & Europe \\
\hline 132. & $8 \mathrm{~N} 139$ & 45.90 & 3 & MT & Anhui Province \\
\hline 133. & $8 \mathrm{~N} 127$ & 46.03 & 3 & MT & Jiangsu Province \\
\hline 134. & 8 N723 & 46.03 & 3 & MT & Washington, United States \\
\hline
\end{tabular}




\begin{tabular}{|c|c|c|c|c|c|}
\hline 135. & $8 \mathrm{~N} 505$ & 46.03 & 3 & MT & Jiangsu \\
\hline 136. & $8 \mathrm{~N} 217$ & 46.30 & 3 & MT & Jiangsu Province \\
\hline 137. & $8 \mathrm{~N} 425$ & 46.30 & 3 & MT & Henan \\
\hline 138. & $8 \mathrm{~N} 762$ & 46.30 & 3 & MT & Former, Soviet Union \\
\hline 139. & $8 \mathrm{~N} 771$ & 46.30 & 3 & MT & Andalucía, Spain \\
\hline 140. & 8 N797 & 46.30 & 3 & MT & Washington, United States \\
\hline 141. & $8 \mathrm{~N} 848$ & 46.30 & 3 & MT & Washington, United States \\
\hline 142. & $8 \mathrm{~N} 220$ & 46.43 & 3 & MT & Shandong Province \\
\hline 143. & 8 N735 & 46.43 & 3 & MT & Andalucía, Spain \\
\hline 144. & $8 \mathrm{~N} 208$ & 46.46 & 3 & MT & Hebei Province \\
\hline 145. & 8 N768 & 46.50 & 3 & MT & Andalucía, Spain \\
\hline 146. & $8 \mathrm{~N} 102$ & 46.63 & 3 & MT & Heilongjiang Province \\
\hline 147. & $8 \mathrm{~N} 413$ & 46.69 & 3 & MT & Henan \\
\hline 148. & $8 \mathrm{~N} 835 \mathrm{~B}$ & 46.69 & 3 & MT & Washington, United States \\
\hline 149. & $8 N 836$ & 46.69 & 3 & MT & Washington, United States \\
\hline 150. & $8 \mathrm{~N} 1009$ & 46.76 & 3 & MT & Shandong Province \\
\hline 151. & $8 \mathrm{~N} 829$ & 46.91 & 3 & MT & Washington, United States \\
\hline 152. & $8 N 750$ & 46.96 & 3 & MT & California, United States \\
\hline 153. & $8 \mathrm{~N} 1010$ & 47.09 & 3 & MT & Shandong Province \\
\hline 154. & $8 \mathrm{~N} 519$ & 47.09 & 3 & MT & Egypt \\
\hline 155. & $8 \mathrm{~N} 404$ & 47.12 & 3 & MT & India \\
\hline 156. & $8 \mathrm{~N} 508$ & 47.22 & 3 & MT & Jiangsu \\
\hline 157. & 8 N749 & 47.22 & 3 & MT & Turkey \\
\hline 158. & ZS-5 & 47.27 & 3 & MT & Shandong Province \\
\hline 159. & $8 \mathrm{~N} 239 \mathrm{~A}$ & 47.31 & 3 & MT & Jiangsu Province \\
\hline 160. & 8N168B & 47.53 & 3 & MT & Yunnan Province \\
\hline 161. & $8 \mathrm{~N} 678$ & 47.55 & 3 & MT & Washington, United States \\
\hline 162. & $8 \mathrm{~N} 259$ & 47.57 & 3 & MT & Jiangsu Province \\
\hline 163. & $8 \mathrm{~N} 250$ & 47.62 & 3 & MT & Yunnan Province \\
\hline 164. & $8 \mathrm{~N} 496$ & 47.62 & 3 & MT & Egypt \\
\hline 165. & $8 \mathrm{~N} 317$ & 47.75 & 3 & MT & Ningxia \\
\hline 166. & $8 \mathrm{~N} 493$ & 47.75 & 3 & MT & Washington, United States \\
\hline 167. & $8 \mathrm{~N} 643$ & 47.80 & 3 & MT & Guizhou \\
\hline 168. & $8 \mathrm{~N} 233 \mathrm{~A}$ & 47.84 & 3 & MT & Hubei Province \\
\hline 169. & $8 \mathrm{~N} 268$ & 47.90 & 3 & MT & Jiangsu Province \\
\hline 170. & 8 N790 & 47.94 & 3 & MT & California United States \\
\hline 171. & $8 \mathrm{~N} 189$ & 48.13 & 3 & MT & Gansu Province \\
\hline 172. & $8 \mathrm{~N} 245$ & 48.15 & 3 & MT & Yunnan Province \\
\hline 173. & $8 \mathrm{~N} 031$ & 48.15 & 3 & MT & Shanghai \\
\hline 174. & $8 \mathrm{~N} 151$ & 48.15 & 3 & MT & Inner Mongolia \\
\hline 175. & $8 \mathrm{~N} 578$ & 48.15 & 3 & MT & Kazakhstan \\
\hline 176. & 8 N752 & 48.15 & 3 & MT & California, United States \\
\hline 177. & $8 N 876$ & 48.15 & 3 & MT & Washington, United States \\
\hline 178. & $8 \mathrm{~N} 888$ & 48.15 & 3 & MT & Washington, United States \\
\hline 179. & $8 \mathrm{~N} 755$ & 48.22 & 3 & MT & Uzbekistan \\
\hline 180. & $8 \mathrm{~N} 429$ & 48.28 & 3 & MT & Henan \\
\hline
\end{tabular}




\begin{tabular}{|c|c|c|c|c|c|}
\hline 181. & $8 \mathrm{~N} 178$ & 48.32 & 3 & MT & Hebei Province \\
\hline 182. & $8 \mathrm{~N} 1044$ & 48.47 & 3 & MT & Shandong Province \\
\hline 183. & $8 \mathrm{~N} 362$ & 48.54 & 3 & MT & Korea \\
\hline 184. & $8 \mathrm{~N} 420$ & 48.54 & 3 & MT & Henan \\
\hline 185. & MS No1 & 48.64 & 3 & MT & Beijing Shi, China \\
\hline 186. & $8 \mathrm{~N} 409$ & 48.68 & 3 & MT & Henan \\
\hline 187. & $8 \mathrm{~N} 626$ & 48.68 & 3 & MT & Guizhou \\
\hline 188. & 8 N736 & 48.68 & 3 & MT & Razgrad, Bulgaria \\
\hline 189. & $8 \mathrm{~N} 763$ & 48.68 & 3 & MT & Former Soviet Union \\
\hline 190. & ZS-8 & 48.74 & 3 & MT & Shandong Province \\
\hline 191. & $8 \mathrm{~N} 498$ & 48.77 & 3 & MT & Egypt \\
\hline 192. & DX CK & 48.93 & 3 & MT & Shandong Province \\
\hline 193. & $8 \mathrm{~N} 274$ & 48.94 & 3 & MT & Jiangsu Province \\
\hline 194. & $8 \mathrm{~N} 401$ & 49.07 & 3 & MT & Hebei Province \\
\hline 195. & 8 N759 & 49.07 & 3 & MT & Nepal \\
\hline 196. & $8 N 782$ & 49.07 & 3 & MT & California, United States \\
\hline 197. & 8 N784 & 49.07 & 3 & MT & California, United States \\
\hline 198. & $8 \mathrm{~N} 740$ & 49.21 & 3 & MT & California, United States \\
\hline 199. & $8 \mathrm{~N} 239$ & 49.34 & 3 & MT & Jiangsu Province \\
\hline 200. & $8 \mathrm{~N} 821$ & 49.34 & 3 & MT & lead the United States \\
\hline 201. & $8 \mathrm{~N} 535$ & 49.52 & 3 & MT & Guizhou \\
\hline 202. & $8 \mathrm{~N} 821$ & 49.56 & 3 & MT & Kazakhstan \\
\hline 203. & $8 \mathrm{~N} 043$ & 49.60 & 3 & MT & Shandong Province \\
\hline 204. & $8 \mathrm{~N} 132$ & 49.60 & 3 & MT & Yunnan Province \\
\hline 205. & 8N796 & 49.60 & 3 & MT & California, United States \\
\hline 206. & $8 \mathrm{~N} 126$ & 49.60 & 3 & MT & Jiangsu Province \\
\hline 207. & $8 \mathrm{~N} 785$ & 49.60 & 3 & MT & Burgas, Bulgaria \\
\hline 208. & $8 \mathrm{~N} 511$ & 49.69 & 3 & MT & Egypt \\
\hline 209. & $8 \mathrm{~N} 200 \mathrm{~B}$ & 50.00 & 3 & MT & Hebei Province \\
\hline 210. & $8 \mathrm{~N} 411$ & 50.00 & 3 & MT & Henan \\
\hline 211. & 8 N921 & 50.00 & 3 & MT & Yunnan Province \\
\hline 212. & $8 \mathrm{~N} 191$ & 50.10 & 3 & MT & Gansu Province \\
\hline 213. & 8 N610 & 50.13 & 3 & MT & Shandong Province \\
\hline 214. & $8 \mathrm{~N} 614$ & 50.26 & 3 & MT & Shandong Province \\
\hline 215. & 8N066 & 50.33 & 3 & MT & Shaanxi Province \\
\hline 216. & 8N072 & 50.40 & 3 & MT & Shaanxi Province \\
\hline 217. & 8N186 & 50.53 & 3 & MT & Hebei Province \\
\hline 218. & 8 N762 & 50.53 & 3 & MT & California, United States \\
\hline 219. & 8N947 & 50.62 & 3 & MT & Yunnan Province \\
\hline 220. & $8 \mathrm{~N} 612$ & 50.66 & 3 & MT & Shandong Province \\
\hline 221. & $8 \mathrm{~N} 868$ & 50.66 & 3 & MT & Uzbekistan \\
\hline 222. & $8 \mathrm{~N} 1015$ & 50.79 & 3 & MT & Shandong Province \\
\hline 223. & 8 N766 & 50.79 & 3 & MT & Andalucía, Spain \\
\hline 224. & $8 \mathrm{~N} 870$ & 50.79 & 3 & MT & Uzbekistan \\
\hline 225. & $8 \mathrm{~N} 623$ & 50.90 & 3 & MT & Guizhou \\
\hline 226. & $8 \mathrm{~N} 725$ & 50.93 & 3 & MT & Pakistan \\
\hline
\end{tabular}




\begin{tabular}{|c|c|c|c|c|c|}
\hline 227. & 8N531 & 51.11 & 3 & MT & Guizhou \\
\hline 228. & $8 N 893$ & 51.16 & 3 & MT & Lead the United States \\
\hline 229. & $8 \mathrm{~N} 620$ & 51.23 & 3 & MT & Shandong Province \\
\hline 230. & $8 \mathrm{~N} 298$ & 51.32 & 3 & MT & Yunnan Province \\
\hline 231. & 8 N644 & 51.32 & 3 & MT & California, United States \\
\hline 232. & $8 \mathrm{~N} 412$ & 51.46 & 3 & MT & Henan \\
\hline 233. & $8 \mathrm{~N} 1008$ & 51.72 & 3 & MT & Shandong Province \\
\hline 234. & $8 N 783$ & 51.72 & 3 & MT & Montana, Bulgaria \\
\hline 235. & 8N035 & 51.85 & 3 & MT & Shandong Province \\
\hline 236. & 8 N769 & 51.85 & 3 & MT & Andalucía, Spain \\
\hline 237. & 8 N788 & 51.85 & 3 & MT & Yambol, Bulgaria \\
\hline 238. & $8 \mathrm{~N} 542$ & 52.03 & 3 & MT & Guizhou \\
\hline 239. & $8 \mathrm{~N} 641$ & 52.03 & 3 & MT & Guizhou \\
\hline 240. & $8 \mathrm{~N} 653$ & 52.20 & 3 & MT & North Macedonia \\
\hline 241. & $8 \mathrm{~N} 275$ & 52.38 & 3 & MT & Beijing Shi, China \\
\hline 242. & 8 N732 & 52.38 & 3 & MT & Beijing Shi, China \\
\hline 243. & $\mathrm{JX}$ & 52.46 & 3 & MT & Shandong Province \\
\hline 244. & $8 \mathrm{~N} 439$ & 52.47 & 3 & MT & Henan \\
\hline 245. & $8 \mathrm{~N} 361$ & 52.73 & 3 & MT & Europe \\
\hline 246. & $8 N 377$ & 52.78 & 3 & MT & Sichuan Province \\
\hline 247. & $8 N 885$ & 52.78 & 3 & MT & lead the United States \\
\hline 248. & $8 \mathrm{~N} 030 \mathrm{~B}$ & 52.78 & 3 & MT & Heilongjiang Province \\
\hline 249. & $8 \mathrm{~N} 613$ & 52.78 & 3 & MT & Shandong Province \\
\hline 250. & $8 \mathrm{~N} 238$ & 52.84 & 3 & MT & Jiangsu Province \\
\hline 251. & $8 \mathrm{~N} 754 \mathrm{~A}$ & 52.91 & 3 & MT & California, United States \\
\hline 252. & 8 N647 & 53.04 & 3 & MT & Serbia \\
\hline 253. & $8 N 867$ & 53.09 & 3 & MT & Uzbekistan \\
\hline 254. & $8 \mathrm{~N} 236$ & 53.15 & 3 & MT & Hubei Province \\
\hline 255. & 8N637 & 53.23 & 3 & MT & Guizhou \\
\hline 256. & $8 \mathrm{~N} 1020$ & 53.44 & 3 & MT & Shandong Province \\
\hline 257. & $8 \mathrm{~N} 021$ & 53.57 & 3 & MT & Hubei Province \\
\hline 258. & $8 \mathrm{~N} 440 \mathrm{~B}$ & 53.62 & 3 & MT & Xinjiang \\
\hline 259. & $8 \mathrm{~N} 509$ & 53.70 & 3 & MT & Jiangsu \\
\hline 260. & $8 \mathrm{~N} 527$ & 53.70 & 3 & MT & Guizhou \\
\hline 261. & 8N706 & 53.70 & 3 & MT & Vermont, United States \\
\hline 262. & $8 \mathrm{~N} 254 \mathrm{~B}$ & 53.78 & 3 & MT & Yunnan Province \\
\hline 263. & $8 \mathrm{~N} 403$ & 53.84 & 3 & MT & Hebei Province \\
\hline 264. & $8 N 787$ & 53.86 & 3 & MT & Pleven, Bulgaria \\
\hline 265. & $8 \mathrm{~N} 413-1$ & 53.97 & 3 & MT & Henan \\
\hline 266. & $8 \mathrm{~N} 222$ & 54.01 & 3 & MT & Shandong Province \\
\hline 267. & $8 \mathrm{~N} 219$ & 54.26 & 3 & MT & Shandong Province \\
\hline 268. & 8N036 & 54.50 & 3 & MT & Shandong Province \\
\hline 269. & $8 \mathrm{~N} 130 \mathrm{~B}$ & 54.50 & 3 & MT & Anhui Province \\
\hline 270. & $8 \mathrm{~N} 263$ & 54.50 & 3 & MT & Jiangsu Province \\
\hline 271. & $8 \mathrm{~N} 060$ & 54.59 & 3 & MT & Shaanxi Province \\
\hline 272. & $8 \mathrm{~N} 027$ & 54.63 & 3 & MT & Jiangxi Province \\
\hline
\end{tabular}




\begin{tabular}{|c|c|c|c|c|c|}
\hline 273. & 8N044 & 54.63 & 3 & MT & Shandong Province \\
\hline 274. & $8 \mathrm{~N} 078 \mathrm{~B}$ & 54.63 & 3 & MT & Thailand \\
\hline 275. & $8 \mathrm{~N} 100$ & 54.63 & 3 & MT & Shanghai \\
\hline 276. & ZS-6 & 54.76 & 3 & MT & Shandong Province \\
\hline 277. & $8 \mathrm{~N} 506$ & 54.98 & 3 & MT & Jiangsu \\
\hline 278. & $8 \mathrm{~N} 586$ & 55.03 & 3 & MT & Guizhou \\
\hline 279. & $8 \mathrm{~N} 047$ & 55.29 & 3 & MT & Shandong Province \\
\hline 280. & $8 \mathrm{~N} 066 \mathrm{~B}$ & 55.42 & 3 & MT & Shaanxi Province \\
\hline 281. & $8 \mathrm{~N} 024$ & 55.42 & 3 & MT & Hubei Province \\
\hline 282. & 8N039 & 55.56 & 3 & MT & Shandong Province \\
\hline 283. & $8 \mathrm{~N} 1038$ & 55.56 & 3 & MT & Shandong Province \\
\hline 284. & $8 \mathrm{~N} 892$ & 55.56 & 3 & MT & Lead the United States \\
\hline 285. & $8 \mathrm{~N} 414$ & 55.69 & 3 & MT & Henan \\
\hline 286. & $8 \mathrm{~N} 621$ & 55.93 & 3 & MT & Shandong Province \\
\hline 287. & $8 \mathrm{~N} 536$ & 55.94 & 3 & MT & Guizhou \\
\hline 288. & $8 \mathrm{~N} 541$ & 56.44 & 3 & MT & Guizhou \\
\hline 289. & $8 \mathrm{~N} 424$ & 56.48 & 3 & MT & Henan \\
\hline 290. & $8 \mathrm{~N} 428$ & 56.48 & 3 & MT & Henan \\
\hline 291. & $8 \mathrm{~N} 590$ & 56.48 & 3 & MT & China \\
\hline 292. & $8 \mathrm{~N} 502$ & 56.72 & 3 & MT & Hubei Province \\
\hline 293. & $8 \mathrm{~N} 125$ & 56.79 & 3 & MT & Jiangsu Province \\
\hline 294. & $8 \mathrm{~N} 231$ & 56.79 & 3 & MT & Hubei Province \\
\hline 295. & 8 N738 & 57.01 & 3 & MT & Plovdiv, Bulgaria \\
\hline 296. & $8 \mathrm{~N} 422$ & 57.41 & 4 & $\mathrm{~S}$ & Henan \\
\hline 297. & $8 \mathrm{~N} 503$ & 57.78 & 4 & $S$ & Jiangsu \\
\hline 298. & $8 \mathrm{~N} 406$ & 58.02 & 4 & $\mathrm{~S}$ & Gansu Province \\
\hline 299. & $8 \mathrm{~N} 312$ & 58.20 & 4 & $\mathrm{~S}$ & Xinjiang \\
\hline 300. & ZS-9 & 58.60 & 4 & $\mathrm{~S}$ & Shandong Province \\
\hline 301. & $8 \mathrm{~N} 556$ & 58.64 & 4 & $\mathrm{~S}$ & Guizhou \\
\hline 302. & $8 \mathrm{~N} 423$ & 58.86 & 4 & $S$ & Henan \\
\hline 303. & $8 \mathrm{~N} 587$ & 58.91 & 4 & $S$ & Shandong Province \\
\hline 304. & $8 \mathrm{~N} 002$ & 59.16 & 4 & $\mathrm{~S}$ & Sichuan Province \\
\hline 305. & 8 N764 & 59.26 & 4 & $\mathrm{~S}$ & Yunnan Sheng \\
\hline 306. & $8 \mathrm{~N} 512$ & 59.47 & 4 & $S$ & Egypt \\
\hline 307. & $8 \mathrm{~N} 273$ & 59.57 & 4 & $\mathrm{~S}$ & Jiangsu Province \\
\hline 308. & $8 \mathrm{~N} 421$ & 59.66 & 4 & $\mathrm{~S}$ & Henan \\
\hline 309. & $8 \mathrm{~N} 560$ & 59.92 & 4 & $\mathrm{~S}$ & Guizhou \\
\hline 310. & 8 N930 & 60.05 & 4 & $\mathrm{~S}$ & USA \\
\hline 311. & $8 \mathrm{~N} 514$ & 60.05 & 4 & $\mathrm{~S}$ & Egypt \\
\hline 312. & $\mathrm{JX}-1$ & 60.74 & 4 & $\mathrm{~S}$ & Shandong Province \\
\hline 313. & 8 N372 & 60.85 & 4 & $\mathrm{~S}$ & Sichuan Province \\
\hline 314. & 8N076 & 60.98 & 4 & $\mathrm{~S}$ & Xinjiang \\
\hline 315. & $8 \mathrm{~N} 566$ & 61.11 & 4 & $\mathrm{~S}$ & Germany \\
\hline 316. & $8 \mathrm{~N} 654$ & 61.42 & 4 & $S$ & North Macedonia \\
\hline 317. & 8 N786 & 62.33 & 4 & $S$ & Burgas, Bulgaria \\
\hline 318. & WQS & 63.16 & 4 & $\mathrm{~S}$ & Shandong Province \\
\hline
\end{tabular}




\begin{tabular}{|c|c|c|c|c|c|}
\hline 319. & $8 \mathrm{~N} 780$ & 63.89 & 4 & $\mathrm{~S}$ & Syria \\
\hline 320. & 8 N629 & 63.89 & 4 & $S$ & Guizhou \\
\hline 321. & $8 \mathrm{~N} 037$ & 64.01 & 4 & $\mathrm{~S}$ & Shandong Province \\
\hline 322. & JX-4 & 64.20 & 4 & $\mathrm{~S}$ & Shandong Province \\
\hline 323. & 8N002B & 64.35 & 4 & S & Sichuan Province \\
\hline 324. & $8 \mathrm{~N} 410$ & 64.51 & 4 & $S$ & Henan \\
\hline 325. & $8 \mathrm{~N} 728$ & 64.81 & 4 & S & Former Soviet Union \\
\hline 326. & $8 \mathrm{~N} 249$ & 65.50 & 4 & $\mathrm{~S}$ & Yunnan Province \\
\hline 327. & 8 N975 & 65.74 & 4 & S & Guizhou Province \\
\hline 328. & $8 \mathrm{~N} 254 \mathrm{~A}$ & 65.78 & 4 & S & Yunnan Province \\
\hline 329. & $8 N 761$ & 65.87 & 4 & $S$ & Former, Soviet Union \\
\hline 330. & $8 \mathrm{~N} 218$ & 66.14 & 4 & S & Jiangsu Province \\
\hline 331. & ZSS & 67.20 & 4 & $S$ & Shandong Province \\
\hline 332. & $8 \mathrm{~N} 324$ & 68.31 & 4 & S & Yunnan Province \\
\hline 333. & 8N013 & 68.58 & 4 & $S$ & Sichuan Province \\
\hline 334. & $8 \mathrm{~N} 529$ & 68.77 & 4 & S & Guizhou \\
\hline 335. & $8 \mathrm{~N} 427$ & 69.75 & 4 & $S$ & Henan \\
\hline 336. & $8 \mathrm{~N} 332$ & 70.49 & 4 & S & Yunnan Province \\
\hline 337. & $8 \mathrm{~N} 561$ & 70.55 & 4 & S & Guizhou \\
\hline 338. & 8 N675 & 72.09 & 4 & S & Poland \\
\hline 339. & $8 \mathrm{~N} 526$ & 72.41 & 4 & S & Guizhou \\
\hline 340. & 8 N950 & 73.15 & 4 & S & USA \\
\hline 341. & 8N030A & 73.41 & 4 & S & Heilongjiang Province \\
\hline 342. & $8 \mathrm{~N} 1040$ & 73.81 & 4 & S & Shandong Province \\
\hline 343. & $8 \mathrm{~N} 545$ & 75.80 & 4 & $\mathrm{~S}$ & Guizhou \\
\hline 344. & 8 N760 & 76.54 & 4 & S & Greece \\
\hline 345. & $8 \mathrm{~N} 559 \mathrm{~B}$ & 77.65 & 4 & S & Guizhou \\
\hline 346. & $8 \mathrm{~N} 1046$ & 79.63 & 4 & S & Shandong Province \\
\hline 347. & 8 N970 & 79.63 & 4 & S & USA \\
\hline 348. & $8 \mathrm{~N} 676$ & 80.56 & 4 & $\mathrm{~S}$ & Syria \\
\hline 349. & $8 \mathrm{~N} 1042$ & 81.48 & 4 & S & Shandong Province \\
\hline 350. & $8 \mathrm{~N} 952$ & 91.53 & 5 & HS & USA \\
\hline 351. & 8 N649 & 95.37 & 5 & HS & North Macedonia \\
\hline 352. & 8 N953 & 96.30 & 5 & HS & USA \\
\hline 353. & $8 \mathrm{~N} 972$ & 96.30 & 5 & HS & USA \\
\hline 354. & 8 N954 & 98.15 & 5 & HS & USA \\
\hline
\end{tabular}

HT, highly tolerant; T, tolerant; S, sensitive; HS, highly sensitive 